\title{
Research
}

\section{Subsidized Fencing of Livestock as a Means of Increasing Tolerance for Wolves}

\author{
Jens Karlsson $^{1}$ and Magnus Sjöström ${ }^{2}$
}

\begin{abstract}
Studies of how proactive measures to reduce livestock depredation by carnivores affect human tolerance toward carnivores are extremely rare. Nevertheless, substantial amounts of money are spent each year on proactive measures to facilitate large carnivore conservation. The objective of this study was to assess how subsidies for proactive measures to reduce sheep losses to wolves are associated with public attitudes toward wolves. The respondents were 445 people living inside wolf territories in Sweden. Our data set is unique because we combine wolf territory level information regarding proactive subsidies and wolf attacks on dogs and sheep with geographical information of the respondents. Consequently, the respondents can be assigned to a specific wolf territory. The number of wolf attacks on sheep and dogs in the respective territories as well as the number of years that the wolf territory had existed did not affect human attitudes toward wolves. Subsidies for proactive measures to reduce wolf predation on sheep significantly increased positive attitudes toward wolf presence on the local scale. The magnitude of the effect of subsidies for proactive measures was comparable to the effect of other variables well known to affect human attitudes toward wolves such as age or education. Our data show that subsidies not only made the already positive more positive, but also made people with negative attitudes to wolf presence locally, less negative. Our conclusion is, therefore, that subsidies for proactive measures are an effective tool when working with "the human dimension" of conservation biology.
\end{abstract}

Key Words: attitudes; depredation; electric fencing; human dimension; proactive measures; wolves

\section{INTRODUCTION}

Human behavior, either deliberate or accidental, legal or illegal, is the main factor affecting distribution and numbers of large carnivores in many parts of the world today (Thiel 1985, Mech et al. 1988, Mladenoff et al. 1995, Mace and Waller 1996, Sunde et al. 1998, Treves and Karanth 2003, Andrén et al. 2006). Conflicts between humans and wildlife is a widespread issue of growing concern for conservationists, especially in relation to large carnivores because they may kill both livestock and humans (Woodroffe et al. 2005). One way to mitigate conflicts between large carnivores and livestock owners is through compensation payments for lost animals, i.e., postconflict mitigation. A second way to mitigate conflicts is to subsidize proactive measures such as fences, i.e., preconflict mitigation.
The objective of compensation programs is to increase human tolerance, which may reduce the illegal killing of large carnivores (Van Tassell et al. 1999). However, compensation programs can be, and are, criticized for being inadequate, complicated, and expensive (Saberwal et al. 1994, Kaczensky 1999, Treves et al. 2002, Montag 2003). After a study in Wisconsin, Naughton-Treves et al. (2003:1509) concluded that, "compensation payments apparently do not improve individual tolerance toward wolves or people's approval of lethal control". Nyhus et al. (2003) suggest that compensation programs need to be a part of a comprehensive approach that includes options for control of offending animals, proactive mitigation measures, and, in some cases, broader financial incentives for changes in land use practices. The latter approach has, for example, been used in India (Gubbi 2006) and African countries (Newmark and Hough 2000).

\footnotetext{
${ }^{1}$ Department of Ecology. Grimsö Wildlife Research Station. Swedish University of Agricultural Sciences., ${ }^{2}$ Department of Economics, Umeå University.
} 
Subsidies for proactive measures to reduce the risk of depredation from large carnivores are used in several countries in Europe, e.g., Sweden, Norway, and Finland, and states in the U.S., e.g., Montana, Wyoming, Idaho, and Minnesota. Subsidies for proactive measures include funding for purchasing and installing permanent electric fences, dogs to guard livestock, and help with temporary measures directly after depredation to prevent repeated losses the following days (Shivik 2006).

Evaluations of the effectiveness of compensation programs are extremely rare and badly needed (Nyhus et al. 2003). Evaluations of government programs that pay farmers for proactive measures are even fewer in number but equally necessary (Gubbi 2006). A first step toward an evaluation of the effectiveness of a program for proactive subsidies would be to assess if there is any association between governmental subsidies and human tolerance of large carnivores.

Age, being a hunter, having a hunter in the family, or living on a farm are almost exclusively reported to be correlated with a more negative attitude toward wolves (Kellert 1985, Bath 1987, Williams et al. 2002, Karlsson and Sjöström 2007). Members of nature conservation NGOs and males generally have a more positive attitude toward wolves compared with other demographic groups (Kellert 1985, Bath 1987, Williams et al. 2002, Karlsson and Sjöström 2007, Broberg and Brännlund 2008).

In addition to the above variables, as is commonly used in studies of human attitudes toward large carnivores, we also used a set of variables characterizing the local wolf presence to avoid omitted variable bias. To control for the possibility of attitudes having changed over time, we have also included a variable capturing the number of years that the respective wolf territories have existed.

Our hypothesis was that subsidies for proactive measures to reduce wolf depredation on livestock does change human attitude toward wolves, i.e., subsidies make humans more positive toward wolf presence. The relatively small wolf population in Sweden, combined with substantial resources spent on documenting wolf territory distribution, and intense documentation of livestock depredation and management measures have resulted in a unique dataset and a possibility to assess the relation between human attitudes and proactive measures. In this paper, we test the effect of subsidies for proactive measures on human attitudes toward wolves.

\section{METHODS}

\section{Data}

In May 2004 a questionnaire was sent to a sample of 4050 persons between 18 and 84 years of age, all over Sweden. After about two weeks, a simple reminder was sent to those who had not responded to the first survey. At the beginning of June the questionnaire was sent again to those who had not yet responded, and at the end of June data collection was closed. A total of 2455 respondents answered the questionnaire, giving a response rate of $60.9 \%$. However, in this paper, we focus on a subsample of the respondents, those living inside the wolf territories in Sweden. The reason for this is that we can then link territory-specific information on wolf attacks on hunting dogs and sheep and governmental subsidies for improved sheep fencing to the respondents within the wolf territories. The study was designed to allow for this kind of analysis by using stratified sampling to obtain enough respondents from the wolf territories, which are sparsely populated. In the wolf territories, 696 out of 1102 persons responded to the questionnaire, giving a response rate of $63.2 \%$.

The questionnaire contained a broad range of questions on attitudes and behavior. The respondents were asked about their socioeconomic status, such as education, number of children, type of housing, and participation in the labor force. The respondents were also asked if they had ever seen a wolf, if they were hunters, if another member of the family was a hunter, and if they were members of any nature conservation NGO. Finally the respondents were asked if they lived on a farm and if they owned livestock. We have also obtained information about gender, income, and age from Statistics Sweden. Definitions of the variables are given in Table 1, and descriptive statistics are given in Table 2. The socioeconomic variables used in this study have been used in many other studies of human attitudes toward large carnivores (e.g., Kellert 1985, Williams et al. 2002, Ericsson and Heberlein 2003). 
Table 1. Definitions of variables used in the analysis.

\begin{tabular}{|c|c|}
\hline Variable & Definition \\
\hline Attitude & $\begin{array}{l}5 \text { if substantial increase, } 4 \text { if modest increase, } 3 \text { if no change, } 2 \text { if modest decrease, } 1 \text { if } \\
\text { substantial decrease, and } 0 \text { if disappearred. }\end{array}$ \\
\hline Age & Years of age. \\
\hline Female & 1 if the respondent is a woman. \\
\hline Income & Total income in the respondent's household. \\
\hline Education & $\begin{array}{l}\text { Level of education: } 1 \text { if compulsory school, } 2 \text { if upper secondary school, and } 3 \text { if } \\
\text { university or university college. }\end{array}$ \\
\hline Farm & 1 if the respondent lives on a farm. \\
\hline Hunter & 1 if the respondent hunts. \\
\hline Hunter in family & 1 if someone else in the respondent's household hunts. \\
\hline Have seen wolf & 1 if the respondent has seen a wolf in the wild. \\
\hline Member & 1 if the respondent is a member of an organization working for conservation of nature. \\
\hline Sheep attack & $\begin{array}{l}\text { Average (over time) proportion of sheep farms that have been attacked by a wolf in the } \\
\text { territory where the respondent lives. }\end{array}$ \\
\hline Dog attack & Average (over time) wolf attacks on dogs in territory where the respondent lives. \\
\hline Exist year & Numbers of years that the respondent's home area has been inside a wolf territory. \\
\hline Fenced proportion & $\begin{array}{l}\text { Proportion of sheep farms that have received subsidies for fencing in the territory where } \\
\text { the respondent lives. }\end{array}$ \\
\hline
\end{tabular}

\section{Study area}

We used a subsample from a nationwide survey (Karlsson and Sjöström 2007). Our subsample consisted of respondents living inside wolf territories. All wolf territories are currently located in south-central Scandinavia between latitude $54^{\circ} \mathrm{N}$ to $75^{\circ} \mathrm{N}$ and longitude $27^{\circ} \mathrm{E}$ to $14^{\circ} \mathrm{E}$ (Fig. 1). The area has an altitude range between 50 and 1000 meters above sea level. This area has a continental climate with average temperatures of $15^{\circ} \mathrm{C}$ in July and about $-7^{\circ} \mathrm{C}$ in January (Swedish Meteorological and Hydrological Institute). From December to March the ground is generally covered with snow of varying depth $(20-50 \mathrm{~cm})$.

Boreal coniferous forests cover most of the area. The most common tree species are Norway spruce
(Picea abies) and Scots pine (Pinus sylvestris), sometimes mixed with birch (Betula pendula, B. pubescens), aspen (Populus tremula), and alder (Alnus incana and A. glutinosa). The area is characterized by intensive forestry with clear-cuts and areas of young forest. Intensive forestry has led to high densities of forest roads. Human population density varies greatly, but averages $<1$ person $/ \mathrm{km}^{2}$ (Wabakken et al. 2001). Potential prey species for wolves in the area are moose (Alces alces), roe deer (Capreolus capreolus), red deer (Cervus elaphus), badger (Meles meles), beaver (Castor fiber), mountain hare (Lepus timidus), capercaillie (Tetrao urogallus), and black grouse (Tetrao tetrix; Olsson et al. 1997). Other large and medium sized predators in the study area are lynx (Lynx lynx), brown bear (Ursus arctos), and red fox (Vulpes vulpes). 
Table 2. Descriptive statistics of the variables used.

\begin{tabular}{llccc}
\hline \hline Variable & Mean & $\begin{array}{c}\text { Standard } \\
\text { deviation }\end{array}$ & Min & Max \\
\hline Attitude & 1.68 & 1.64 & 0 & 5 \\
Female & 0.43 & 0.49 & 0 & 1 \\
Age & 52.3 & 15.9 & 19 & 85 \\
Income (Thousand Swedish Crowns) & 240 & 142 & 0 & 1496 \\
Education & 1.59 & 0.71 & 1 & 3 \\
Hunter & 0.22 & 0.43 & 0 & 1 \\
Hunter in family & 0.21 & 0.42 & 0 & 1 \\
Member & 0.07 & 0.27 & 0 & 1 \\
Farm & 0.30 & 0.49 & 0 & 1 \\
Have seen wolf & 0.37 & 0.48 & 0 & 1 \\
Sheep attack & 0.02 & 0.03 & 0 & 0.13 \\
Dog attack & 0.32 & 0.26 & 0 & 1 \\
Exist year & 5.11 & 2.19 & 1 & 8 \\
Fenced proportion & 0.49 & 0.36 & 0 & 1 \\
\hline
\end{tabular}

\section{Wolf population status and census methods}

The Scandinavian wolf population of Sweden and Norway has been growing in range and numbers since the 1980s (Wabakken et al. 2006). The core of the wolf population is situated in south-central Sweden, outside the mountainous part of Scandinavia that is used for semidomestic reindeer husbandry. In 2003, the number of wolf reproductions was nine, and the total wolf population was estimated to be just below 100 individuals in Sweden (Aronson et al. 2003).

The county administrative boards are responsible for finding all new wolf territories and determining their approximate size and geographical distribution. Field personnel in each county administrative board conduct survey transects by car and snowmobile during winter. In summer, wolf observations and DNA from scats are used to find newly formed territories. Given the limited size and distribution of the Scandinavian wolf population and the high density of local roads, which improves wolf census efficiency, it is very unlikely that new wolf territories are formed without detection. Wolf territories in our study had existed between one and eight years.

\section{Wolf depredation}

In Sweden, wolves attacked 100-200 sheep and 15-25 dogs, mainly hunting dogs, each year prior to this survey (Swedish Wildlife Damage Centre 2007). Owners of livestock that was killed, injured, or missing after an attack from large carnivores are compensated at a rate slightly higher than the market value. We argue that the number of killed, injured, or missing sheep not reported is small because sheep must be grazed in small fenced pastures, and 
because of the relatively small number of sheep on each sheep farm. Ninety-two percent of Swedish sheep farms have fewer than 50 ewes (Statistics Sweden 2006). Furthermore, there is an animal welfare law that compels sheep owners to check and count their sheep at least once a day. All farms reporting suspected depredation are visited by government personnel trained to examine carcasses and to determine the true cause of death or injury. All carcasses are skinned and examined. No compensation is paid unless trained government personnel attribute death or injury to large carnivores, which further motivates farmers to report suspected depredation.

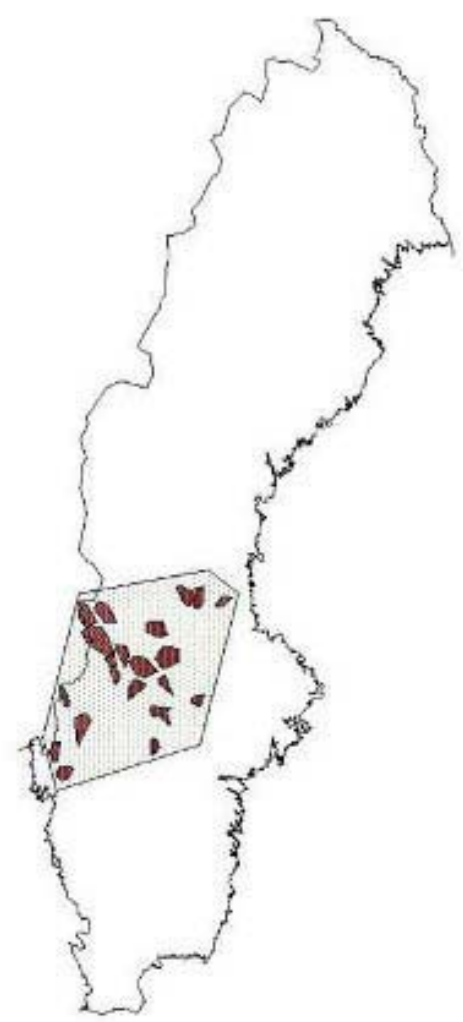

Fig 1. Map of Sweden with our study area and polygons for the respective wolf territories.

The Swedish government started subsidizing the installation of predator-proof electric fences in the early 1990s, and the fencing scheme has gradually been extended. In 2005, the Swedish government paid EUR 1,000,000 as subsidies for electric fencing to 289 farmers, mainly in wolf territories. In addition to the materials, the subsidies also pay for the labor involved in installing the fences. The compensation for livestock killed by wolves in Sweden the same year totaled EUR 70,000, which corresponds to about $7 \%$ of the money spent on compensation and proactive measures that year. The purpose of the program for subsidizing proactive measures is to increase tolerance of wolves and wolf management.

The government fencing scheme has mainly subsidized three fence types: electric netting fence, electric strained-wire fence, and woven wire fence supplemented with one or two live wires. All fences are designed to protect livestock against brown bear, wolf, and lynx.

Data on fence subsidies was obtained from records of fence subsidy approvals by county administrative boards. Based on the address of the farm receiving the subsidy, the location of subsidized fences was determined to the level of postal code area, village, or farm. If properly maintained, predator-proof fences will last for 10-15 years. Therefore, the measures to reduce livestock depredation with subsidized predator-proof fencing was regarded as an accumulative process within the study period, in which new farms with predator-proof fences add to the level of protection achieved by earlier predatorproof fencing.

In this paper we combine several data sets at wolf territory level. First, we had geographical information about the respondents that made it possible to assign them to a specific wolf territory. Second, we had data on wolf attacks on hunting dogs and sheep farms in the specific wolf territories. Finally, we had data on sheep farms that had received governmental subsidies for improved fencing in the specific wolf territories. Put together, this has resulted in a unique dataset that enabled us to explicitly test the impact of proactive subsidies at a local level on the attitudes toward wolves, while controlling for the local situation in terms of wolf attacks on sheep and dogs within the specific wolf territories.

\section{STATISTICAL ANALYSES}

To test our hypothesis, we used an ordered probit model. The basic idea behind this setup is that people have an underlying notion of their attitudes 
toward wolves, and that these attitudes will be determined by personal characteristics according to:

$$
y_{i}^{*}=\beta^{\prime} x_{i}+u_{i}
$$

where $y_{i}^{*}$ is attitudes on the real number line, $x_{i}$ is a vector of observable personal characteristics, $u_{i}$ is a vector of unobservable personal characteristics, and $\beta$ is a vector of parameters. In this paper, we use two categories of independent variables: (1) socioeconomic variables commonly used in studies of human attitudes toward wildlife such as age, gender, income, education, having a farm, or being a hunter (Kellert 1985, Bath 1987, Dahle 1987, Bjerke et al. 1998, Williams et al. 2002), and (2) wolf territory-specific variables describing the situation in the territories (Table 1). One variable expresses the number of years that the wolf territory has existed, and two variables capture the rate of wolf attacks on sheep and dogs, respectively. To get an estimate of $y_{i}^{*}$ the respondents were asked: "What trend would you like to see in wolf numbers in your home area? Possible answers were: disappear (0), substantial decrease (1), modest decrease (2), no change (3), modest increase (4), substantial increase (5), and don't know (not included in the analyses). This implies that the dependent variable will be an ordered categorical variable, thereby making the ordered probit model suitable for estimation. This kind of model has been used for a wide range of topics, including attitudes. For an extensive introduction to the field of ordered models, see Cameron and Trivedi (1998).

Consequently, the observed and discrete value of attitudes $y_{i}$ is assumed to be determined by the underlying continuous variable $y_{i}^{*}$ and the cut-off points $u_{\mathrm{i}}$ given by the possible response alternatives. By coding the responses of "disappear," "substantial decrease," "modest decrease," "no change," "modest increase," and "substantial increase" as $0,1,2,3,4$, and 5, and assuming that is independent with a normal standard distribution, we obtain a discrete choice model of the observed responses.

The parameters are estimated by maximum likelihood and should be interpreted with caution because they do not express marginal effects of the independent variables on the dependent variable. However, the marginal effects of the regressor on the underlying variable can be inferred.

\section{RESULTS}

The response frequencies within wolf territories on the attitude question showed that $15.8 \%$ were in favor of an increase in the number of wolves in their home area, whereas $24.1 \%$ would have liked no change. Also, $18.5 \%$ were in favor of a decrease of wolves in their home area, $35.6 \%$ expressed that they would like the wolves to disappear, and the remaining $6 \%$ gave no response at all (Table 3 ).

Respondents' attitudes toward wolf presence on a local scale (Table 4) was significantly affected (positively correlated) by the variable subsidies for proactive measures. The variables "number of wolf attacks on sheep and dogs" as well as "number of years that the territory has existed" did not significantly affect respondent attitudes. Thus, we cannot reject our hypothesis; that subsidies for proactive measures to reduce wolf depredation on livestock does increase public tolerance for wolves.

The effects of the independent variables on attitudes may differ between those who would like to see an increase in the wolf population locally and those who would like the wolf population to decrease or disappear locally. Therefore, it is important to know whether the positive effect of subsidies was primarily driven by those who support an increase in the local wolf population. As a consequence, we have also estimated an attitude model for those that responded "disappear," "substantial decrease," "modest decrease," and "no change," i.e., we excluded those who supported an increase in wolf numbers in the home area. The qualitative results remained and, although the significance level decreased slightly, the effect of the variable proportion of farms with subsidized fences was still positive and significant $(\mathrm{p}=0.03)$.

\section{DISCUSSION}

In this study, we were primarily interested in testing the effect on human attitudes of subsidies for proactive measures to reduce predation on sheep. Variables such as age, education, membership in a nature conservation group, or being a hunter have commonly been shown to affect attitudes toward wolves in previous studies (Kellert 1985, Bath 1987, Biggs 1988, Bjerke et al. 1998, Williams et al. 2002, Ericsson and Heberlein 2003). Those variables were also significant in our study (Table 4). Because the effect of these variables is thoroughly reviewed by, 
Table 3. Attitudes toward wolves, measured as the frequencies of supported scenarios of wolf population trends in the wolf territory where the respondent lives.

\begin{tabular}{lc}
\hline \hline Attitude & Local development of wolves $(\mathrm{n}=672)$ \\
\hline Substantial increase & $5.6 \%$ \\
Modest increase & $10.2 \%$ \\
No change & $24.1 \%$ \\
Modest decrease & $8.2 \%$ \\
Substantial decrease & $10.3 \%$ \\
Disappear & $35.6 \%$ \\
Don't know & $6.0 \%$ \\
\hline
\end{tabular}

for example, Williams et al. (2002), we do not discuss them in this paper.

The proportion of sheep farms that had received fencing subsidies was significantly associated with increased tolerance for local wolf presence. Standardized coefficients (Table 4) indicated that this variable was just as strong a predictor of human attitudes as other commonly used variables, such as level of education or age. One possible mechanism behind this effect may be that the mere existence of a subsidy program convinces the public that the negative aspects of wolf presence are taken seriously by the authorities. It is also likely that the general public, through media, public meetings and discussions, has become aware of whether a large or a small proportion of the sheep farms in the wolf territory area has received subsidies and new fences. The proportion of the sheep farmers that had received fencing subsidies may then have served as an indicator of how seriously the authorities regard negative effects on a local scale. Fencing subsidies may thus increase positive local attitudes toward wolf-human coexistence.

In a 2003 study, Naughton-Treves et al. showed that compensating for livestock killed by wolves did not affect attitudes toward wolves. The suggested reason for this lack of effect was that attitudes toward wolves are based on values and formed early in life. Subsidies for proactive measures may give sheep farmers concrete assistance in mitigating conflicts with wolves, and may also give sheep farmers and the informed public a sense that their concerns and problems are being seriously considered and addressed. We believe this has resulted not in humans being more eager to have wolves in their area, but in humans being less eager not to have wolves in their area. This is supported by the fact that even when we excluded the respondents who where positive to wolf presence, i.e., respondents who wanted a substantial increase or moderate increase in wolf numbers in their area, subsidies remained a significant variable. Thus, subsidies not only make the already positive more positive, but also the already negative, less negative. In other words, subsidies for proactive measures did not increase human value of wolves, but made humans more tolerant to having wolves present in their vicinity.

Direct experience of wolf presence as well as experience of wolf depredation on sheep and dogs may cause negative attitudes toward wolves, as suggested by Williams et al. (2002), Boninger et al. (1995), and Petty et al. (1997). To control for the possibility of attitudes having changed over time, we also surveyed other variables related to direct experience with wolves, i.e., if the respondent had seen wolves or not, the proportion of sheep farms per year that had been attacked by wolves, number of dogs that had been attacked by wolves per year 
Table 4. Parameter estimates for the attitude model. A negative sign on the parameter implies negative effect on the dependent variable when the independent variable increases.

\begin{tabular}{lcc}
\hline \hline Variable & Standardized coefficients & p-value \\
\hline Female & -0.020 & 0.606 \\
Age & -0.140 & $\mathbf{0 . 0 0 0}$ \\
Income & -0.046 & 0.268 \\
Education & 0.110 & $\mathbf{0 . 0 0 5}$ \\
Hunter & -0.155 & $\mathbf{0 . 0 0 0}$ \\
Hunter in family & -0.133 & $\mathbf{0 . 0 0 0}$ \\
Member & 0.142 & $\mathbf{0 . 0 0 0}$ \\
Farm & -0.085 & $\mathbf{0 . 0 1 2}$ \\
Have seen wolf & -0.126 & $\mathbf{0 . 0 0 0}$ \\
Sheep attack & -0.020 & 0.444 \\
Dog attack & 0.001 & 0.836 \\
Exist year & -0.063 & 0.116 \\
Fenced proportion & 0.122 & $\mathbf{0 . 0 0 2}$ \\
\hline
\end{tabular}

Log likelihood -632.5

Sample size: 445

in the respective territories, and the number of years that the wolf territory had existed. Neither the proportions of sheep farms that had experienced depredation nor the number of dogs attacked by wolves had any significant effect on human tolerance toward wolves. However, respondents that had actually seen a wolf in the wild were more negative toward wolves than those who had not seen one. There have been no reports of wolves behaving aggressively or threatening humans in other ways in the surveyed territories. Seeing a wolf does not necessarily turn a person's positive attitude toward wolves to a negative one, or vice versa. Moreover, seeing a wolf may serve as a reminder of personally held values and affect the degree of negative attitudes and the will to express them. The frequency of wolf sightings may thus exacerbate the attitude of people already negative toward wolf conservation.
In Sweden, few sheep farmers depend on their sheep or lamb production economically. We therefore recommend readers to apply our results with caution, especially in areas of the world where humans depend heavily on the resources that should be protected from wildlife.

The ultimate measure of the effectiveness of a program for proactive subsidies could be the number or proportion of legally and illegally killed carnivores. However, data on illegally killed large carnivores is difficult and costly to gather and estimate accurately, and it is not easy to find control areas with which to compare. We therefore believe that a first and relevant step toward an evaluation of the effectiveness of a program for proactive subsidies is to assess if there is any association between governmental subsidies and human tolerance of large carnivores. 


\section{CONCLUSIONS}

Subsidies for proactive measures affect human attitudes toward wolves. The magnitude of the effect is comparable to the effect of other variables well known to influence human attitudes toward wolves, such as age or education. It should in most cases be far easier to use proactive measures compared with altering age or level of education among humans in a certain region. Our conclusion is therefore that subsidies for proactive measures can be used as an effective tool when working with "the human dimension" of conservation biology of large carnivores.

Responses to this article can be read online at: http://www.ecologyandsociety.org/voll6/iss 1/art16/ responses/

\section{Acknowledgments:}

H., Andrén, H., Hammar, H. Sand, L. Svensson and four anonymous reviewers gave valuable comments on previous drafts of this manuscript. The authors greatly acknowledge financial support from FORMAS.

\section{LITERATURE CITED}

Andrén, H., J. D. C. Linnell, O. Liberg, R. Andersen, A. Danell, J. Karlsson, J. Odden, P. F. Moa, P. Ahlqvist, T. Kvam, R. Franzén, and P. Segerström. 2006. Survival rates and causes of mortality in Eurasian lynx Lynx lynx in multi-use landscapes. Biological Conservation 131:23-22.

Aronson, A., P. Wabakken, H. Sand, O. K. Steinseth, and I. Kojola. 2003. The wolf in Scandinavia: status report of the 2001/2002 winter. No. 2. Høgskolen i Hedmark, Evenstad, Norway.

Bath, A, J. 1987. Attitudes of various interest groups in Wyoming toward wolf reintroduction in Yellowstone National Park. Thesis, University of Wyoming, Laramie, Wyoming, USA.

Biggs, J, R. 1988. Reintroduction of the Mexican wolf into New Mexico-an attitude survey. Thesis, New Mexico State University, Las Cruces, New Mexico, USA.
Bjerke, T., T. S. Ødegårdstuen, and B. P. Kaltenborn. 1998. Attitudes toward animals among Norwegian children and adolescents: species preferences. Anthrozoos 11:227-235.

Boninger, D. S., J. A. Krosnick, and M. K. Berent. 1995. Origins of attitude importance: self-interest, social identification, and value relevance. Journal of Personality and Social Psychology 68:61-80.

Broberg, M., and R. Brännlund. 2008. An alternative interpretation of multiple bounded WTP data certainty dependent payment card intervals. Resource and Energy Economics 30:555-567.

Cameron, C., and P. Trivedi. 1998. Regression analysis of count data. Cambridge University Press, Cambridge, UK.

Dahle, L. 1987. Attitudes towards bears, wolverines and wolves in Norway. Thesis, Agricultural University of Norway, Oslo, Norway.

Ericsson, G., and T. A. Heberlein. 2003. Attitudes of hunters, locals, and the general public in Sweden now that the wolves are back. Biological Conservation 111:149-159.

Gubbi, S. 2006. Tiger habitats and integrated conservation and development projects: a case study from Periyar Tiger Reserve, India. Thesis, Durrell Institute of Conservation and Ecology, University of Kent, Canterbury, UK.

Kaczensky, P. 1999. Large carnivore depredation on livestock in Europe. Ursus 11:59-72.

Karlsson, J., and M. Sjöström. 2007. Human attitudes towards wolves, a matter of distance. Biological Conservation 137:610-616.

Kellert, S. R. 1985. The public and the timber wolf in Minnesota. Transactions of North American Wildlife and Natural Resources Conference 51:193-200.

Mace, R. D., and J. S. Waller. 1996. Grizzly bear distribution and human conflicts within Jewel Basin hiking area, Swan Mountains, Montana. Wildlife Society Bulletin 24:461-467.

Mech, L. D., S. H. Fritts, G. L. Radde, and W. J. Paul. 1988. Wolf distribution and road density in Minnesota. Wildlife Society Bulletin 16:85-87. 
Mladenoff, D., T. A. Sickley, R. G. Haight, and A. Wydewen. 1995. A regional landscape analysis and prediction of favourable gray wolf habitat in the Northern Great Lakes region. Conservation Biology 9:279-294.

Montag, J. 2003. Compensation and predator conservation: limitations of compensation. Carnivore Damage Prevention News 6:2-6.

Naughton-Treves, L., R. Grossberg, and A. Treves. 2003. Paying for tolerance: rural citizens' attitudes toward wolf depredation and compensation. Conservation Biology 17:1500-1511.

Newmark D. W., and J. L. Hough. 2000. Conserving wildlife in Africa: integrated conservation development projects and beyond. BioScience 50 (7):585-592.

Nyhus, P. J., H. Fisher, F. Madden, and S. Osofsky. 2003. Taking the bite out of wildlife damage: the challenges of wildlife compensation schemes. Conservation in Practice 4:39-41.

Olsson, O., J. Wirtberg, M. Andersson, and I. Wirtberg. 1997. Wolf (Canis lupus) predation on moose (Alces alces) and roe deer (Capreolus capreolus) in southcentral Scandinavia. Wildlife Biology 3:13-25.

Petty, R. E., D. T. Wegener, and L. R. Fabrigar. 1997. Attitudes and attitude change. Annual Review of Psychology 48:609-674.

Saberwal, V. K., J. P. Gibbs, R. Chellam, and A. J. T. Johnsingh. 1994. Lion-human conflict in the Gir forest, India. Conservation Biology 8:501-507.

Statistics Sweden. 2006. Jordbruksstatistisk årsbok. Statistics Sweden, Örebro, Sweden. [online] URL: http://www.sjv.se/download/18.50cb 902d1234ca17a7e8000554/statistisk +årsbok+2006. pdf.

Shivik, J. A. 2006. Tools for the edge: whats new for conserving carnivores? Bioscience 56:253-259.

Swedish Wildlife Damage Centre. 2007. Viltskadestatistik 2006. Statistics of wildlife damages. Swedish University of Agricultural Sciences, Uppsala, Sweden. [online] URL: http://www.viltskadecenter. se.
Sunde, P., Ø. Snorre, and T. Kvam. 1998. Tolerance to humans of resting lynx Lynx lynx in a hunted population. Wildlife Biology 4:177-183.

Thiel, R. P. 1985. The relationship between road densities and wolf habitat suitability in Wisconsin. American Midland Naturalist 113:404-407.

Treves, A., R. Jurewicz, L. Naughton-Treves, R. Rose, and A. Wydeven. 2002. Wolf depredation on domestic animals in Wisconsin, 1976-2000. Wildlife Society Bulletin 30:231-241.

Treves, A. and K. U. Karanth. 2003. Humancarnivore conflict and perspectives on carnivore management worldwide. Conservation Biology 17:1491-1499.

Van Tassell, L. W., C. Phillips, and B. Yang. 1999. Depredation claim settlements in Wyoming. Wildlife Society Bulletin 27:479-487.

Wabakken, P., H. Sand, O. Liberg, and A. Bjärvall. 2001. The recovery, distribution, and population dynamics of wolves on the Scandinavian peninsula, 1978-1998. Canadian Journal of Zoology 79:710-725.

Wabakken, P., Å. Aronson, T. Strömseth, H. Sand, L. Svensson, and I. Kojola. 2006. The wolf in Scandinavia: status report of the 2005-200 winter. Högskolan i Hedmark, Viltskadecenter, Grimsö forskningsstation, Vilt- och fiskeriforskningen, Oulu. Høskolen i Hedmark, Norway.

Williams, C. K., G. Ericsson, and T. A. Heberlein. 2002. A quantitative summary of attitudes toward wolves and their reintroduction 1972-2000. Wildlife Society Bulletin 30:575-584.

Woodroffe, R., S. Thirgood, and A. Rabinowitz. 2005. People and wildlife. Conflict or coexistence. Cambridge University Press, Cambridge, UK. 